\title{
Degumming of Raw Silk Fabric with Help of Marine Extracellular Protease
}

\author{
${ }^{1}$ Das Sumana, ${ }^{2}$ Mathummal Sudarshan, ${ }^{3}$ Ashoke Ranjan Thakur and ${ }^{1}$ Shaon RayChaudhuri \\ ${ }^{1}$ Department of Biotechnology, School of Biotechnology and Biological Sciences, \\ West Bengal University of Technology, BF-142, Sector-I, Salt Lake, Kolkata-700064, India \\ ${ }^{2}$ Inter University Consortium, Sector-III/Plot LB-8, Bidhan Nagar, Kolkata-700098, India \\ ${ }^{3}$ Vice Chancellors's Unit, Techno India University, EM-4/1, Sector-V, Salt Lake, Kolkata-700009, India \\ Received 2012-11-23, Revised 2013-01-12; Accepted 2013-01-27
}

\begin{abstract}
Protease secreting microbe was isolated and characterized on the basis of their morphological, biochemical, physiological and 16S rDNA based molecular properties. The extracellular protease was quantified and characterized. Protease was used for different time $(4,8,12$ and $24 \mathrm{~h})$ at different temperature (RT and $\left.37^{\circ} \mathrm{C}\right)$ for optimization of the degumming process for raw silk fabric with enzyme dosage $\left(0.2-1 \mathrm{unit} / \mathrm{cm}^{2}\right.$ of fabric). Post-enzymatic treatment, the fabric quality and texture was compared with conventionally treated as well as untreated fabric in terms of degumming loss, tensile strength and yarn count and colour fastness to light/water. The isolate SM1 (Bacillus thuringensis) was able to grow in Carbon Minimal Salt Medium $(\mathrm{CMSM})$ with jaggery or tamarind as the carbon source $(0.3 \% \mathrm{w} / \mathrm{v})$. Energy Dispersive X-Ray Fluorescense (EDXRF) data showed intracellular accumulation of heavy metal by the isolate. Extracellular protease was able to degum silk fabric within $4 \mathrm{~h}$ at RT with enzyme concentration of 0.8 unit $/ \mathrm{cm}^{2}$ and the maximum degumming loss was $21.72 \%$. Post enzymatic degumming, a shiny texture was observed under Environmental Scanning Electron Microscope (ESEM) and the yarn volume also increased. Utilization of CMSM made the process cost effective during large scale application. Intracellular metal accumulation and growth in a wide range of temperature and $\mathrm{pH}$ made the isolate a potential candidate for bioremediation. Extracellular protease with significant degumming property could be used as an eco friendly approach as compared to the conventional chemical treatment.
\end{abstract}

Keywords: Marine Coast, Protease, Bioremediation, Degumming

\section{INTRODUCTION}

Larva of some insects and arachnids produce silk to fabricate structures such as cocoon, webs, nets and egg stalk. However, silk thread spun by the larva of silk worm, Bombyx mori is commercially important and has a great value in textile industry. Some of the properties like, fitness, strength, elasticity, dye ability, softness, flexibility, smooth feeling, lusture, elegance and grace make silk fiber valuable in textile industry (Trotman, 1970). Silk fiber consists of the two fibrous proteins, fibroin and a gummed amorphous protein named sericin, which cements the fibroin fibers together. Fibroin and sericin proteins are present in about 75 and $25 \%$ of total weight respectively. Fibroin protein is a high molecular weight polypeptide $(\simeq$ $350 \mathrm{KDa})$, composed of glycine, alanine and serine in molecular ratio $3: 2: 1$, with a six residue repetition of (Gly-Ser-Gly-Ala-Gly-Ala)n (Zhou et al., 2000). Three types of silk fiber conformations are found in nature: a helical conformation, an antiparallel $\beta$-sheet and a random coil without definite order. The most commonly found structure is antiparallel $\beta$-sheet (Zhang et al., 2002), where Gly side chains are extended from one surface and it's Ser and Ala side chains are extending from the other surface. Silk Corresponding Author: Shaon RayChaudhuri, Department of Biotechnology, School of Biotechnology and Biological Sciences, West Bengal University of Technology, BF-142, Sector-I, Salt Lake, Kolkata-700064, India 
fibroin also has a region where bulk residues such as Tyr, Val, Arg and Asp are present.

Degumming is a process where sericin is totally removed from the fibroin wall to obtain shine, smoothness and other properties (Freddi et al., 2003). A series of steps are involved in the silk processing: reeling, weaving, degumming, dyeing/printing and finishing. After degumming, the silk fiber becomes shinny and its elasticity improves. The post degumming condition of silk fiber, such as handling, lusture and rubbing behavior is greatly dependant on the quantity of sericin remaining on the silk fibroin. In conventional process silk fiber is boiled in an aqueous solution containing soap, alkali, synthetic detergent and organic acids (Bianchi and Colonna, 1992; Freddi et al., 1996). Nowadays in batch degumming process soap is replaced with synthetic detergent to compensate the acidity of sericin hydrolysis. During conventional silk degumming process associated hydrolytic degradation of fiber leads to change in physical properties such as dull appearance, surface fibrillation and tensile strength (Freddi et al., 2003).

Enzymatic treatment of silk fiber as an alternative of conventional process is now in focus. Alkaline proteases perform better than other proteases (acid and neutral) with respect to uniform sericin removal and improvement of silk quality. In comparison with conventional process there are certain drawbacks which are found in enzymatically degummed silk fiber quality: higher shear and bending rigidity, lower fullness and softness to handle, remnant of the sericin at cross over points between wrap and weft (Chopra et al., 1996). Inspite of lower performance and higher cost of enzyme compared to chemical, enzymatic treatment attract the attention of scientists and technologists for the ecofriendly aspect of the process (Duran and Duran, 2000; Gubitz and Cavaco-Paulo, 2001). Enzymatic degumming process would save the resources in terms of water, energy, chemicals and reduce the cost of effluent treatment.

The present study focuses on the application of marine microbial protease in degumming of raw silk fabric. The aim of the study was: (i) Isolation of an industrially important protease producing strain and its characterization, (ii) Characterization of the extracellular protease, (iii) Studying the degumming kinetics and (iv) Developing an enzyme based degumming process which can compete with conventional treatment in terms of post treatment quality of fabric. Here the quality of silk fabric is reported by degumming loss calculation, tensile strength, colour fastness to light and water, yarn count and Scanning Electron Microscopic (SEM) analysis.

\section{MATERIALS AND METHODS}

\subsection{Sample Collection and Isolation of Extracellular Protease Producing Pure Isolate}

Water sample was collected from coastal region of Mandarmani $\left(21^{\circ} 37.012^{\prime} \mathrm{N} / 87^{\circ} 29.881^{\prime} \mathrm{E}\right)$, West Bengal, India and $50 \mu \mathrm{L}$ of water was spread on milk media (Adarsh et al., 2007) plate to isolate protease secreting strain. The protease producing strain was subsequently purified by repeated streaking. Later the culture was maintained in Luria Bertenni broth (LB) at $37^{\circ} \mathrm{C}$ with shaking at $150 \mathrm{rpm}$. It was stored at $-80^{\circ} \mathrm{C}$ as $50 \%$ glycerol stock for long term and on LB agar plate for short term.

\subsection{Characterization of Isolate}

Morphological structures and Gram characteristics were confirmed using light microscopy (1000X magnification on a Zeiss Axiostar Plus microscope) as well as Environmental scanning electron microscopy (FEI QUANTA 200 MARK 2 at $15 \mathrm{kV}$ ) (Adarsh et al., 2007). Gram character was reconfirmed by Real time PCR analysis (Shigemura et al., 2005). Detailed biochemical (DNase, oxidase, lipase, lecithinase, catalase and amylase) and physiological (optimum $\mathrm{pH}$ and temperature for bacterial growth, growth kinetics, utilization of different substrates as carbon source, antibiotic sensitivity and metal tolerance ability) characterizations were done following the protocol of (Nandy et al., 2007; Roy et al., 2008).

DNA extracted from the isolate by modified alkali lysis method (RayChaudhuri et al., 2006) was amplified using the following primer: Forward primer -5' AGA GTT TGA TCA TGG CTC 3' and Reverse primer-5' CTA GCG ATT CCG ACT TCA 3' (RayChaudhuri and Thakur, 2006). The $50 \mu \mathrm{L}$ reaction mixture was prepared [Template- $30 \mathrm{ng}, 0.25 \mu \mathrm{L}$ (from $50 \mathrm{pmole} / \mu \mathrm{L}$ stock) of each of forward and reverse primer, PCR Ready Mix (Sigma)-12.5 $\mu \mathrm{L}$ and triple distilled sterile water to make up the volume to $25 \mu \mathrm{L}$ ] and was subjected to 40 cycles according to the program-Initial denaturation $92^{\circ} \mathrm{C}-2$ min then 40 cycles of $92^{\circ} \mathrm{C}-1 \mathrm{~min} ; 50^{\circ} \mathrm{C}-1$ min; $72^{\circ} \mathrm{C}-2 \mathrm{~min}$ and final hold at $4^{\circ} \mathrm{C}$. 16SrDNA PCR product of isolate SM1 was sequenced using Applied Biosystems (ABI) partial sequencing kit and the sequences were subjected to BLAST analysis followed by GenBank submission and phylogenetic tree construction using neighbour joining method. 


\subsection{Determination of Enzyme Activity}

Using Azocasein as a substrate, effect of temperature and $\mathrm{pH}$ on the activity of extracellular protease of the isolate was determined by the method mentioned by (Malathu et al., 2008). One unit of activity was defined as the amount of enzyme required to produce an increase of 0.1 absorbance (OD at $440 \mathrm{~nm}$ ).

Extracellular cell free supernatant was incubated within the range of $4-60^{\circ} \mathrm{C}$ for $12 \mathrm{~h}$ and enzyme assay was measured using Azocasein method.

For observing the effect of $\mathrm{pH}$, extracellular cell free supernatant was taken and the $\mathrm{pH}$ was adjusted with $6 \mathrm{~N}$ $\mathrm{HCl}$ and $4 \mathrm{~N} \mathrm{NaOH}$ within the range of 2-12 and protease activity was measured by Azocasein method at $440 \mathrm{~nm}$.

\subsection{Optimization of Silk Fabric Degumming Conditions}

Raw silk fabrics were incubated for different time intervals $(4,8,12$ and $24 \mathrm{~h})$ at $\mathrm{RT}$ as well as $37^{\circ} \mathrm{C}$ to observe the degumming loss with enzyme in material-toliquor ratio 1:200. Inactivation of enzyme was carried out in hot water bath followed by cold water and the sample was air dried. After that, raw silk fabrics were incubated with different enzyme dosage $\left(0.2-1 \mathrm{unit} / \mathrm{cm}^{2}\right.$ of fabric) for $4 \mathrm{~h}$ at RT (optimum condition). Optimum $\mathrm{pH}$ and temperature for the enzyme function was maintained throughout the tests. All degumming tests were performed in triplicate.

\subsection{Comparative Study of Silk Degumming}

Raw silk fabric was incubated with enzyme at optimum condition of silk degumming (in terms of time, temperature and enzyme concentration) in material-toliquor ratio of 1: 200. In case of control sample LB was used instead of enzyme and incubated under same condition. In case of alkaline bath wash, silk fabric was treated with $10 \mathrm{~g} \mathrm{~L}^{-1}$ soap and $2 \mathrm{~g} \mathrm{~L}^{-1}$ sodium carbonate in a liquor ratio $(1: 30)$ at $90-95^{\circ} \mathrm{C}$ for $45 \mathrm{~min}$. All of the degummed (enzymatic treatment, control and alkali wash) silks were then washed with hot water followed by cold water and air dried. Weight of the cloths were taken pre and post incubation and weight loss due to degumming was calculated (Nakpathom et al., 2009).

Colour fastness to light and water, tensile strength and yarn count of four silk samples were determined by standard ISO method: BS EN ISO 105 BO2 BW-4, BS EN ISO 105-E01, BS EN ISO 13934:II and ISO 7211-5 respectively.
Raw silk treated with extracellular enzyme of SM1 (as treated), alkali washed, LB broth (as control) and untreated samples were further used for Scanning Electron Microscopic (SEM) analysis. Change in the fabric condition was observed by comparing the Scanning Electron Micrograph (SEM) of treated and untreated samples [FEI QUANTA 200 MARK 2 at 10 and $15 \mathrm{kV}$ acceleration].

\section{RESULTS}

\subsection{Isolation and Characterization of Isolate}

Depending on the casein degrading ability on the milk media plate, SM1, a protease producing strain was isolated from Mandarmani coastal region, with $99.86 \%$ identity with Bacillus thuringensis [FJ377720] at the molecular level (16SrDNA sequence). SM1 was a spore forming, Gram positive diplobacilli. Upon environmental scanning electron microscopy, a connected pattern was observed between two and more cells, which may be due to presence of pilli. SM1 did not possess capsule or flagella. The biochemical characterization of the isolate revealed it to be catalase, oxidase and DNase positive with no growth on lecithinase medium (Hichrome Aureus media). It was able to degrade starch, but did not produce lipase. Thus two industrially important enzymes like protease and amylase were found in SM1.

The $\mathrm{pH}$ and temperature profile for the isolate indicated that it was able to grow within a wide range of temperature $\left(20-40^{\circ} \mathrm{C}\right)$ and $\mathrm{pH}(6-12)$ with the optimum growth at $37^{\circ} \mathrm{C}$ and $\mathrm{pH}$ of 7 . Under optimum condition of growth SM1 showed an efficient growth with a lag phase of $2 \mathrm{~h}$, followed by extended logarithmic phase of $8 \mathrm{~h}$ and stationary phase. Variation in growth in presence of different substrates was observed, with maximum growth in LB followed by Tamarind and Jaggery $(0.3 \%$ $\mathrm{w} / \mathrm{v}$ as carbon source in carbon minimal salt media).

Isolate was resistant to following antibiotics ampicillin, cloxacillin, ceftazidime, metronidazole, polymyxin $\mathrm{B}$, rifampicin and trimethoprin and sensitive to tetracycline, doxycycline hydrochloride, gentamicin, norfloxacin and ciprofloxacin.

Isolate was able to grow in presence of a wide range of metal salts, indicating its tolerance to different metals. SM1 was also able to accumulate five common environmental contaminants, among which it showed highest accumulation in case of $\mathrm{Pb}(11268.28 \mathrm{ppb})$, followed by $\mathrm{Cr}$ (18.33ppb), Ni (9.53ppb), Cu (3.23ppb) and Co (1.95ppb) as evident from the Energy Dispersive $\mathrm{X}$ Ray Fluorescence (EDXRF) analysis. 
Das Sumana et al. / American Journal of Biochemistry and Biotechnology 9 (1): 12-18, 2013

Table 1. Analysis of silk quality on the basis of different parameter: colour fastness to light and water, yarn count and tensile strength of treated and untreated silk fibers

\begin{tabular}{|c|c|c|c|c|c|}
\hline \multirow{2}{*}{$\begin{array}{l}\text { Degumming } \\
\text { Methods }\end{array}$} & \multirow{2}{*}{$\begin{array}{l}\text { Colour fastness } \\
\text { to water }{ }^{\text {a }}\end{array}$} & \multicolumn{2}{|c|}{ Yarn count (in Denier) } & \multicolumn{2}{|c|}{ Tensile strength (in $\mathrm{Kg}$ ) } \\
\hline & & Warp & Weft & Warp & Weft \\
\hline Chemical treatment & 4 & 20.1 & 34.5 & 7.7 & 26.9 \\
\hline Enzymatic Treatment & 4 & 64.5 & 64.3 & 11.2 & 29.6 \\
\hline Treated with LB & 4 & 34.3 & 28.7 & 12.1 & 30.1 \\
\hline Untreated & 4 & 34.2 & 64.1 & 11.3 & 30.3 \\
\hline
\end{tabular}

; The rating scale of colour fastness to light and water is from 1 (poor) to 5 (excellent)

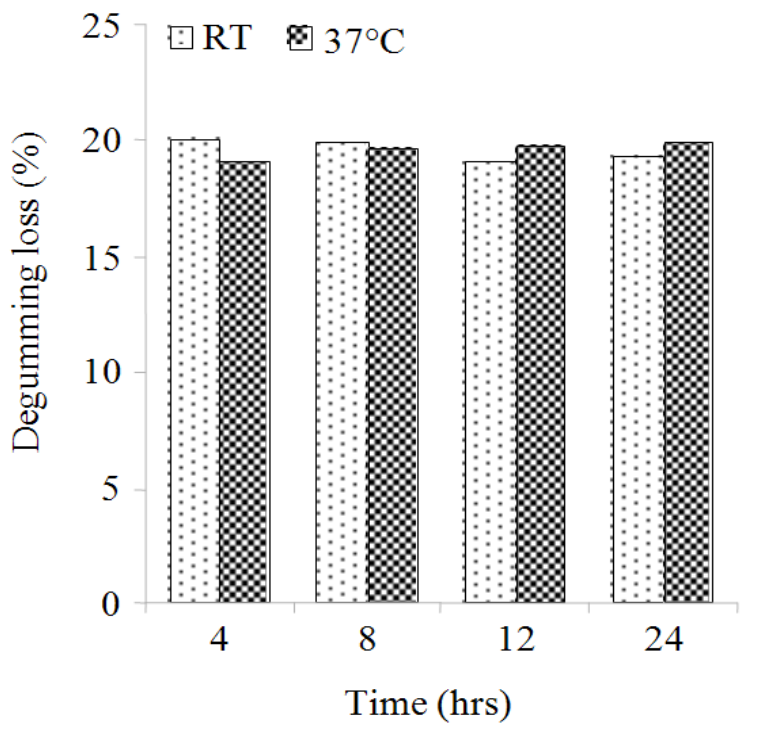

(a)

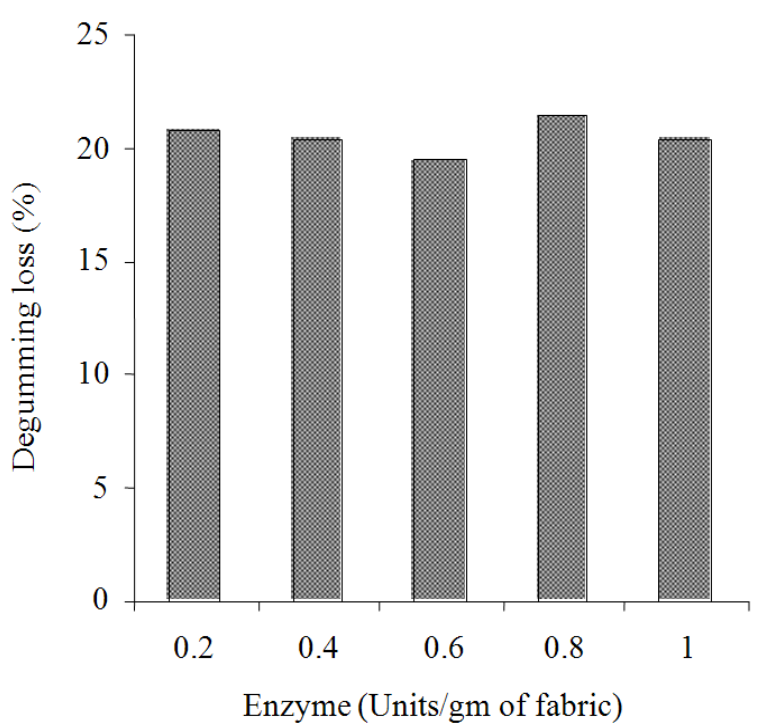

(b)

Fig. 1. Representing the degumming kinetics: effect of enzyme dosage and time, a. the maximum $(21.72 \%)$ percentage of degumming loss was observed within $4 \mathrm{~h}$ at RT, when raw silks fabrics were incubated for different time intervals $(4,8,12$ and $24 \mathrm{~h}$ ) at RT as well as $37^{\circ} \mathrm{C}$ to observe the degumming loss with enzyme in material-to-liquor ratio 1:200. b. revealed that when silk fabric was incubated at RT for $4 \mathrm{~h}$ with different enzyme dosage (0.2-1 unit/gm of fabric), it was found that at dosage of 0.8 units/gm of fabric, degumming loss (\%) was maximum.

\subsection{Determination of Enzyme Activity}

The extracellular protease was stable at wide range of temperature $\left(4-60^{\circ} \mathrm{C}\right.$ ) and $\mathrm{pH}$ (4-9) with optimum performance at $40^{\circ} \mathrm{C}$ and $\mathrm{pH} 7$.

\subsection{Silk Degumming}

\subsubsection{Study of Degumming Kinetics: Effect of Enzyme Dosage and Time}

Degumming loss at different incubation periods clearly indicated the optimum incubation time to be within 4 h (Fig. 1a). Figure 1b reflected 0.8 unit $/ \mathrm{cm}^{2}$ of enzyme to be optimum for degumming. The bar height corresponded to the degumming loss.
Degumming loss of silk fiber with alkali soap wash and enzymatic treatment was 28.0 and $21.72 \%$ respectively, whereas the degumming loss by LB was negligible $4.2 \%$. The efficiency of protease secreted from SM1, in degumming of raw silk was quite satisfactory; it helped to remove the sericin from the raw silk fiber, which was also observed during SEM analysis. SEM analysis revealed that sericin was removed from the fabrics which were treated both conventionally as well as enzymatically (Fig. 2). The gum material stuck on fabric (as observed in untreated sample) was found to be removed in treated fabric and thus it leading to shiny appearance. The yarn also became loose with associated volume increase (Table 1). 


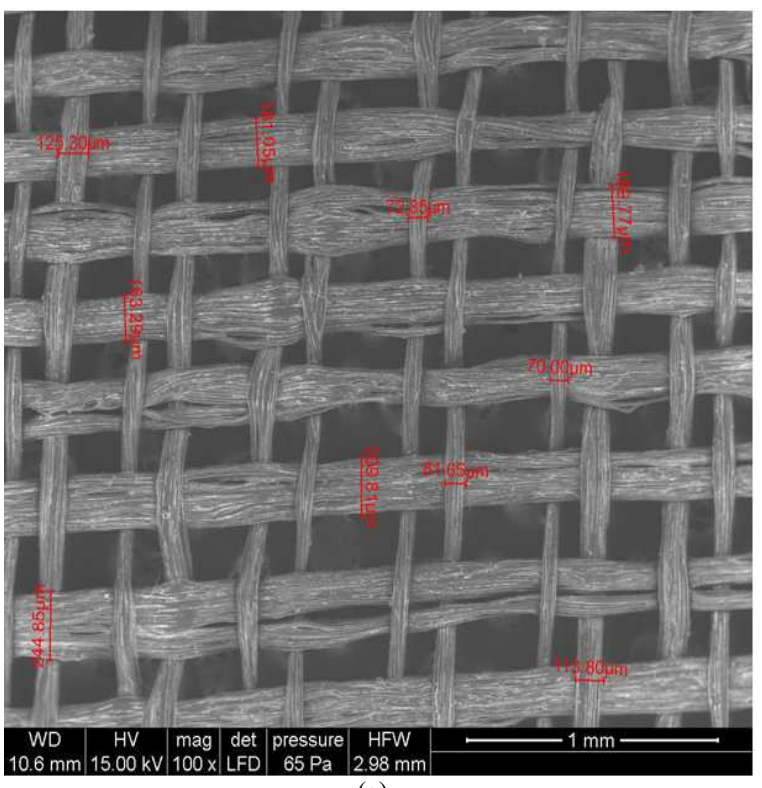

(a)

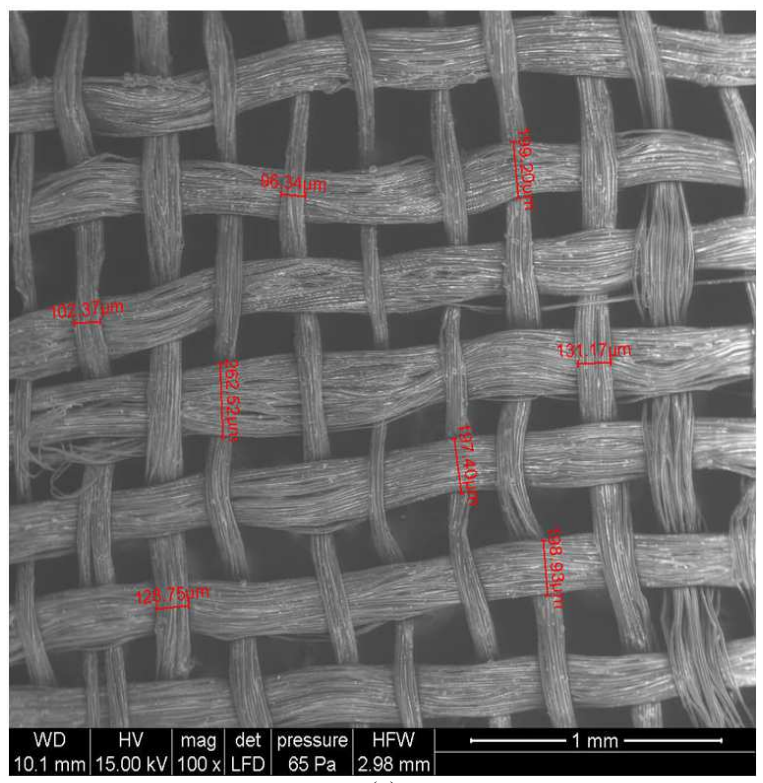

(c)

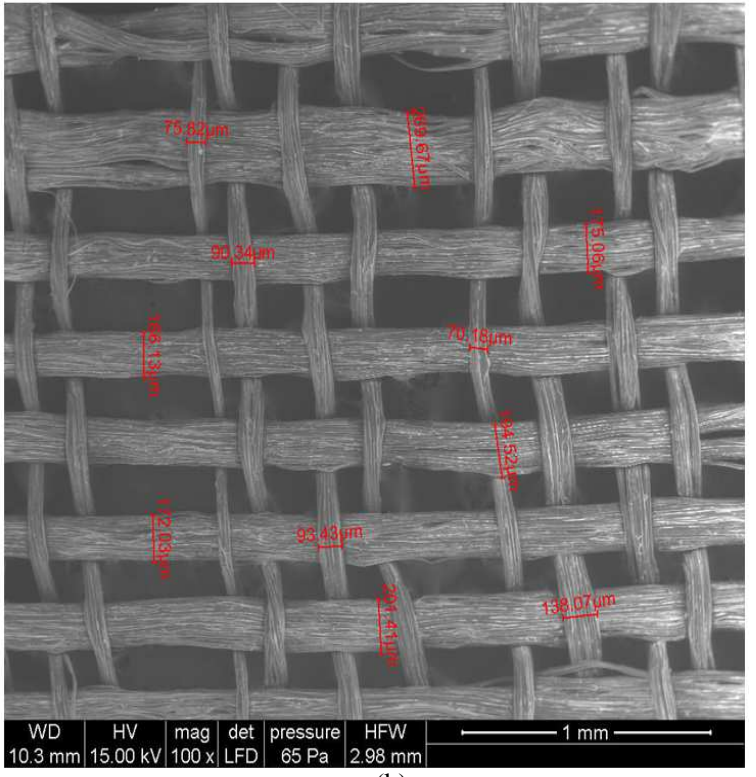

(b)

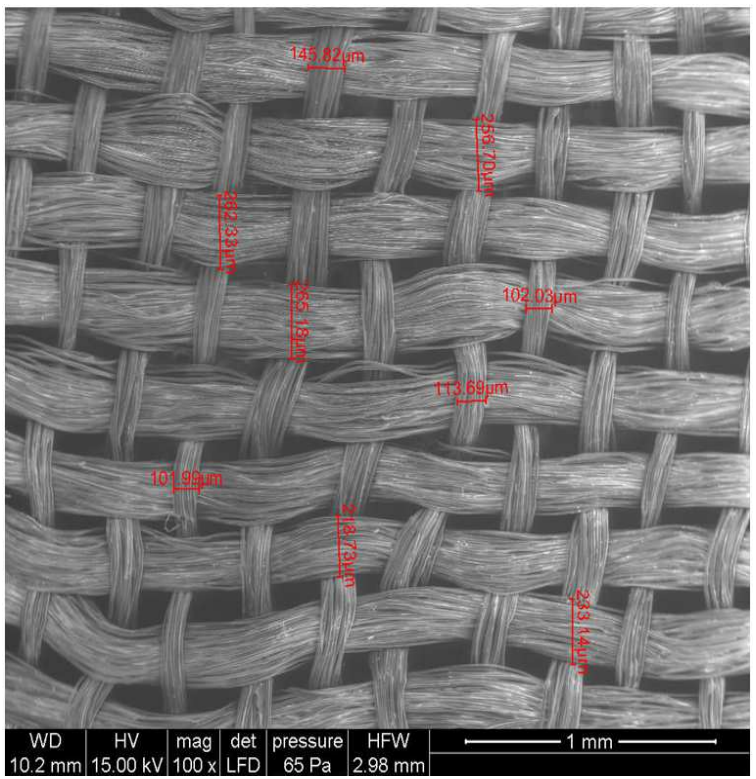

(d)

Fig. 2. Representing the scanning electron micrograph image of (a) untreated; (b) treated with LB only; (C) treated through conventional method and (d) enzymatic treated raw silk fabric. It was observed that volume of raw silk fiber was increased by enzymatic treatment rather than untreated sample. This is due to removal of sericin by the enzyme and the texture become shiny

\section{DISCUSSION}

The characterization of the isolate reveals its Gram characteristics and ability to survive under stressful environment like marine coastal saline water. The presence of enzymes like catalase and oxidase also help them to survive in adverse condition. Amylases especially alkaline amylases are used in detergent industry and also have use in food and beverages (baking), brewing, starch and alcohol industries. As amylase degrades starch into 
amylose and amylopectin, it is also used as digestive aid. Utilization of Tamarind and Jaggery as the carbon sources $(0.3 \% \mathrm{w} / \mathrm{v}$ as carbon source in carbon minimal salt media) for microbial growth makes the process economical at large scale. The extent of accumulation of heavy metal makes the isolate a potent bioremedial candidate to remove the toxic metal from the contaminated environmental site. Ability of the isolate to grow in a wide range of temperature and $\mathrm{pH}$ makes it suitable for various industrial and bioremedial applications.

Silk fiber contains $30 \%$ Sericin. In terms of measurement of degumming loss, conventional method almost reached the target level of sericin removal, whereas the enzymatic treatment was far beneath the target level. This may be due to the temperature in which degumming is performed; sericin needs a higher temperature for removal from the fiber stick. The mechanical agitation could also help in improving the degumming quality which was absent during lab scale enzymatic treatment. Degumming loss was negligible $(4.2 \%)$ in absence of enzyme, though it is well known that water alone can remove sericin at higher temperature (110-120 $\left.{ }^{\circ} \mathrm{C}\right)$ under high pressure.

The change in volume (increase/shrinkage) of warp and weft is known as take-up, which depends on the fabric texture and treatment. Warp and weft counts depend on the fabric condition. When the fabric was observed under SEM, the yarn width was found to increase after enzymatic treatment, whereas after conventional treatment the width of yarn was found to shrink (decreased in width). This may be due to the higher twist, which was also reconfirmed by the value of yarn count. Tensile strength remained same after enzymatic treatment of silk in comparison with untreated sample, but it decreased for chemical treatment. Using harsh chemicals may be the cause of deterioration of silk quality, which was reflected as shrinking of the weft and tensile strength. There was no difference in colour fastness to water for four processes, whereas the quality of silk after enzymatic treatment decreased in colour fastness to light (data not shown). Use of mild alkali in lower amount with enzyme might improve the quality of colour fastness to light. Inspite of all these points, the ability of this protease for degumming is unquestionable, it could be an environment friendly approach as compared to the use of surfactants for this purpose.

\section{CONCLUSION}

The isolate SM1 (Bacillus thuringensis) isolated from Mandarnmani coastal region in West Bengal, India could be used as a potent bioremedial candidate for its intracellular metal accumulating property (Chowdhury et al., 2011) The extracellular protease of the isolate was able to perform degumming of raw silk fabric in significant amount. After the enzymatic treatment, texture of the fabric became shiny and the volume of the yarn increased. The other properties of the fabric like tensile strength, yarn count, colour fastness to water either improved or remained unchanged after the enzymatic treatment in comparison with untreated sample, except for colour fastness to light. With some minor modification in the process, like introduction of mechanical agitation or use of mild alkali, the enzymatic treatment procedure could be improved.

\section{ACKNOWLEDGEMENT}

The researchers acknowledge the support of the West Bengal University of Technology for the computational facility and the laboratories; University Grant Commision-Inter University Consortium for the student fellowship as well as Department of Atomic Energy, Government of India under the BRNS scheme for financial assistance. The authors would like to thank the World Bank under the TEQIP program for providing the publication fee.

\section{REFERENCES}

Adarsh, V.K., M. Mishra, S. Chowdhury, M. Sudarshan and A.R. Thakur et al., 2007. Studies on metal microbe interaction of three bacterial isolates from East Calcutta Wetland. Online J. Biol. Sci., 7: 80-88. DOI: 10.3844/ojbsci.2007.80.88

Bianchi, A.S. and G. M. Colonna, 1992. Developments in the degumming of silk. Melliand Textilberichte, 73: 68-75.

Chopra, S., R. Chattopadhyay and M.L. Gulrajani, 1996. Low stress mechanical properties of silk fabric degummed by different methods. J. Textile Inst., 87: 542-553. DOI: 10.1080/00405009608631356

Chowdhury, S., A.R. Thakur and S. RayChaudhuri, 2011. Novel microbial consortium for laboratory scale lead removal from city effluent. J. Environ. Sci. Technol., 4: 41-54.

Duran, N. and M. Duran, 2000. Enzyme applications in the textile industry. Rev. Prog. Coloration, 30: 4144. DOI: $10.1111 /$ j.1478-4408.2000.tb03779.x

Freddi, G., G. Allara and G. Candiani, 1996. Degumming of silk fabrics with tartaric acid. J. Soc. Dyers Colour, 112: 191-195. DOI: 10.1111/j.14784408.1996.tb01817.x 
Freddi, G., R. Mossotti and R. Innocenti, 2003. Degumming of silk fabric with several proteases. J. Biotechnol., 106: 101-112. DOI: 10.1016/j.jbiotec.2003.09.006

Gubitz, G.M. and A. Cavaco-Paulo, 2001. Biotechnology in the textile industry--perspectives for the new millennium. J. Biotechnol., 89: 89-90. PMID: 11500200

Malathu, R., S. Chowdhury, M. Mishra, S. Das and P. Moharana et al., 2008. Characterization and wash performance analysis of microbial extracellular enzymes from East Calcutta Wetland in India. Am. J. Applied Sci., 5: 1650-1661. DOI: 10.3844/ajassp.2008.1650.1661

Nakpathom. M., B. Somboon and N. Narumol, 2009. Papain enzymatic degumming of Thai Bombyx mori silk fibers. J. Microscopy Soc. Thailand, 23: 142146.

Nandy, P., A.R. Thakur and S. RayChaudhuri, 2007. Characterization of bacterial strains isolated through microbial profiling of urine samples. Online J. Biol. Sci., 7: 44-51. DOI: 10.3844/ojbsci.2007.44.51

RayChaudhuri, S. and A.R. Thakur, 2006. Microbial genetic resource mapping of East Calcutta wetlands. Curr. Sci. Ind., 91: 212-217.

RayChaudhuri, S., A.K. Pattanayak and A.R. Thakur, 2006. Microbial DNA extraction from sample of varied origin. Curr. Sci. Ind., 91: 1697-1700.
Roy, S., K. Mishra, S. RayChaudhuri, A.R. Thakur and S. Raychaudhuri, 2008. Isolation and characterization of novel metal accumulating extracellular protease secreting bacteria from marine coastal region of Digha in West Bengal, India. Online J. Biol. Sci., 8: 25-31. DOI: 10.3844/ojbsci.2008.25.31

Shigemura, K., T. Shrikawa, H. Okada, K. Tanaka and S. Kamidono et al., 2005. Rapid detection and differentiation of Gram-negative and Gram-positive pathogenic bacteria in urine using TaqMan probe. Clin. Exp. Med., 4: 196-201. DOI: 10.1007/s10238004-0056-X

Trotman, E.R., 1970. Dyeing and Chemical Technology of Textile Fibres. 4th Edn., Griffin, London, ISBN10: 0852641656, pp: 378.

Zhang, H., J. Magoshi, M, Becker, J.Y. Chen and R. Matsunaga, 2002. Thermal properties of Bombyx mori silk fibers. J. Applied Polym. Sci., 86: 1817 1820. DOI: 10.1002/app.11089

Zhou, C.Z., F. Confalonieri, N. Medina, Y. Zivanovic and C. Esnault et al., 2000. Fine organization of Bombyx mori fibroin heavy chain gene. Nucl. Acids Res., 28: 2413-2419. 